\title{
Myxobolus cerebralis internal transcribed spacer 1 (ITS-1) sequences support recent spread of the parasite to North America and within Europe
}

\author{
Christopher M. Whipps ${ }^{1, *}$, Mansour El-Matbouli ${ }^{2}$, Ronald P. Hedrick ${ }^{3}$, Vicki Blazer ${ }^{4}$, \\ Michael L. Kent ${ }^{1}$
}

${ }^{1}$ Department of Microbiology, Center for Fish Disease Research, 220 Nash Hall, Oregon State University, Corvallis, Oregon 97331-3404, USA

${ }^{2}$ Institut für Zoologie, Fischerei-Biologie und Fischkrankheiten der Universität München, Kaulbachstr. 37, 80539 München, Germany ${ }^{3}$ Department of Medicine and Epidemiology, School of Veterinary Medicine, University of California, Davis, California 95616, USA

${ }^{4}$ US Geological Survey, National Fish Health Research Laboratory, Leetown Science Center, 11700 Leetown Road, Kearneysville, West Virginia 25430, USA

\begin{abstract}
Molecular approaches for resolving relationships among the Myxozoa have relied mainly on small subunit (SSU) ribosomal DNA (rDNA) sequence analysis. This region of the gene is generally used for higher phylogenetic studies, and the conservative nature of this gene may make it inadequate for intraspecific comparisons. Previous intraspecific studies of Myxobolus cerebralis based on molecular analyses reported that the sequence of SSU rDNA and the internal transcribed spacer (ITS) were highly conserved in representatives of the parasite from North America and Europe. Considering that the ITS is usually a more variable region than the SSU, we reanalyzed available sequences on GenBank and obtained sequences from other $M$. cerebralis representatives from the states of California and West Virginia in the USA and from Germany and Russia. With the exception of 7 base pairs, most of the sequence designated as ITS-1 in GenBank was a highly conserved portion of the rDNA near the 3-prime end of the SSU region. Nonetheless, the additional ITS-1 sequences obtained from the available geographic representatives were well conserved. It is unlikely that we would have observed virtually identical ITS-1 sequences between European and American $M$. cerebralis samples had it spread naturally over time, particularly when compared to the variation seen between isolates of another myxozoan (Kudoa thyrsites) that has most likely spread naturally. These data further support the hypothesis that the current distribution of $M$. cerebralis in North America is a result of recent introductions followed by dispersal via anthropogenic means, largely through the stocking of infected trout for sport fishing.
\end{abstract}

KEY WORDS: Myxozoa $\cdot$ Ribosomal DNA $\cdot$ Myxobolus cerebralis $\cdot$ Whirling disease $\cdot$ Internal transcribed spacer

Resale or republication not permitted without written consent of the publisher

\section{INTRODUCTION}

One of the most frequently cited examples of myxozoan parasitism is whirling disease, caused by Мухоbolus cerebralis. Symptoms of the disease include skeletal deformities, blackened tails and characteristic whirling behavior (Gilbert \& Granath 2003). The parasite has been found in 26 countries around the world
(Bartholomew \& Reno 2002), and it is widely accepted that this distribution is a result of anthropogenic movement of fish (Wolf 1986, Hedrick et al. 1998). Hoffman (1970) proposed that brown trout in Germany were the natural host for the parasite and that it was through movement of infected rainbow trout from this area that the spread to North America resulted. Presumably, this same mechanism was involved in the spread to other 
countries such as New Zealand and South Africa. Determining whether population structure exists for this parasite, and therefore genetically distinct populations, may be important in the identification of potential hot spots as reservoirs of infection, especially within the USA. M. cerebralis has been observed in 22 states in the USA (Bartholomew \& Reno 2002) and there is great concern for wild trout populations as this parasite becomes enzootic in streams where fish were previously uninfected.

\section{MATERIALS AND METHODS}

Molecular approaches for resolving relationships among the Myxozoa have relied mainly on small subunit (SSU) ribosomal DNA (rDNA) sequence analysis (Kent et al. 2001). The conservative nature of this gene, however, may make it inadequate for intraspecific comparison. Generally, the internal transcribed spacer (ITS) regions of the rDNA are usually much more variable than the SSU, and are therefore useful for intraspecific comparisons (van Herwerden et al. 2000). Andree et al. (1999) compared the SSU and ITS sequences from representatives of Myxobolus cerebralis from Germany, West Virginia, and California and reported that there were more sequence differences within the SSU than in the ITS.

To verify this result, we reexamined the ITS-1 sequences of Andree et al. (1999) (GenBank accession numbers AF115256-AF115260) using the basic local alignment search tool (BLAST) (Altschul et al. 1990) and sequence alignments. Searches were conducted in GenBank using the nucleotide-nucleotide BLAST. Sequence alignments of the above Myxobolus cerebralis sequences to metazoan rDNA were performed in Clustal X (Thompson et al. 1997) using the following sequences: Kudoa thyrsites (AY078430), Homo sapiens (HSU13369), Drosophila melanogaster (M21017), Aurelia aurita (AY039208), Oncorhynchus mykiss (AF308735).

The best matches with the BLAST were the SSU sequence of several myxozoans and other invertebrate taxa. We verified these results with our SSU rDNA alignments (Fig. 1). Clearly, a majority of the sequence identified as ITS-1 by Andree et al. (1999) (all but 7 base pairs, bp) corresponds to the highly conserved 3-prime region of the SSU rDNA. These results prompted us to reexamine the ITS region of Myxobolus cerebralis.

The DNA from actinospore (triactinomyxon) and myxospore stages of Myxobolus cerebralis or from tissues of infected rainbow trout were obtained from the following locations: actinospores in $95 \%$ ethanol from California and Russia, rainbow trout heads from West Virginia, and myxospore DNA from Germany. For polymerase chain reactions (PCR), DNA was extracted via the DNeasy Tissue kit (QIAGEN), or individual actinospores were collected for direct use in $\mathrm{PCR}$ reactions. The ITS-1, 5.8S, and ITS-2 region from the California $M$. cerebralis was amplified in a PCR reaction using standard conditions (Whipps et al. 2003) with the following primers. Primer Mc18S1F (5' AAT ACG CTG GGA TCG ATG) was complementary to the 3-prime region of the SSU and used with the reverse primer 28S1R (5' GTG TTT CAA GAC GGG TCG), a general large subunit (LSU) primer of Whipps et al. (2004). The resulting 1670 bp fragment was cloned into plasmids (QIAGEN) and 3 clones were sequenced in both directions.

\section{RESULTS AND DISCUSSION}

Clone sequences were almost identical and have been deposited in GenBank (AY479922-AY479924). Start and stop positions (Fig. 2) of ITS-1, 5.8S and ITS2 regions were approximated from alignments of SSU, $5.8 \mathrm{~S}$ and LSU sequences of a broad range of metazoan taxa. The ITS-1 sequence was approximately $410 \mathrm{bp}$ long with an AT content of $65 \%$ (as opposed to a $50 \%$ AT content in the SSU). From Myxobolus cerebralis ITS-1 clone sequences, we observed 3 variable nucleotide positions and a single insertion-deletion (indel), representing a sequence variability of $1.7 \%$ between clones from a single sample. The 5.8S rDNA was 176

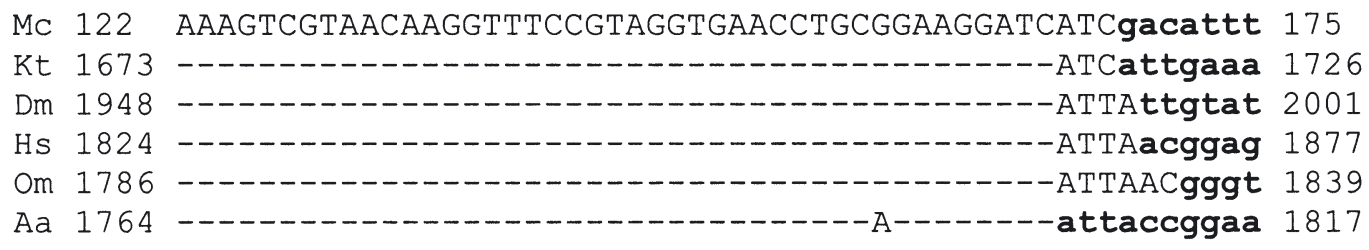

Fig. 1. Alignment of 3-prime end of small subunit (SSU) ribosomal DNA (rDNA) to Myxobolus cerebralis (Mc) sequence of Andree et al. (1999) (AF115256), illustrating its identity to this highly conserved region. Other taxa in alignment were: Kt, Kudoa thyrsites (AY078430); Dm, Drosophila melanogaster (M21017); Hs, Homo sapiens (HSU13369); Om, Oncorhynchus mykiss (AF308735); and Aa, Aurelia aurita (AY039208). ITS-1 start indicated by lowercase letters in bold 


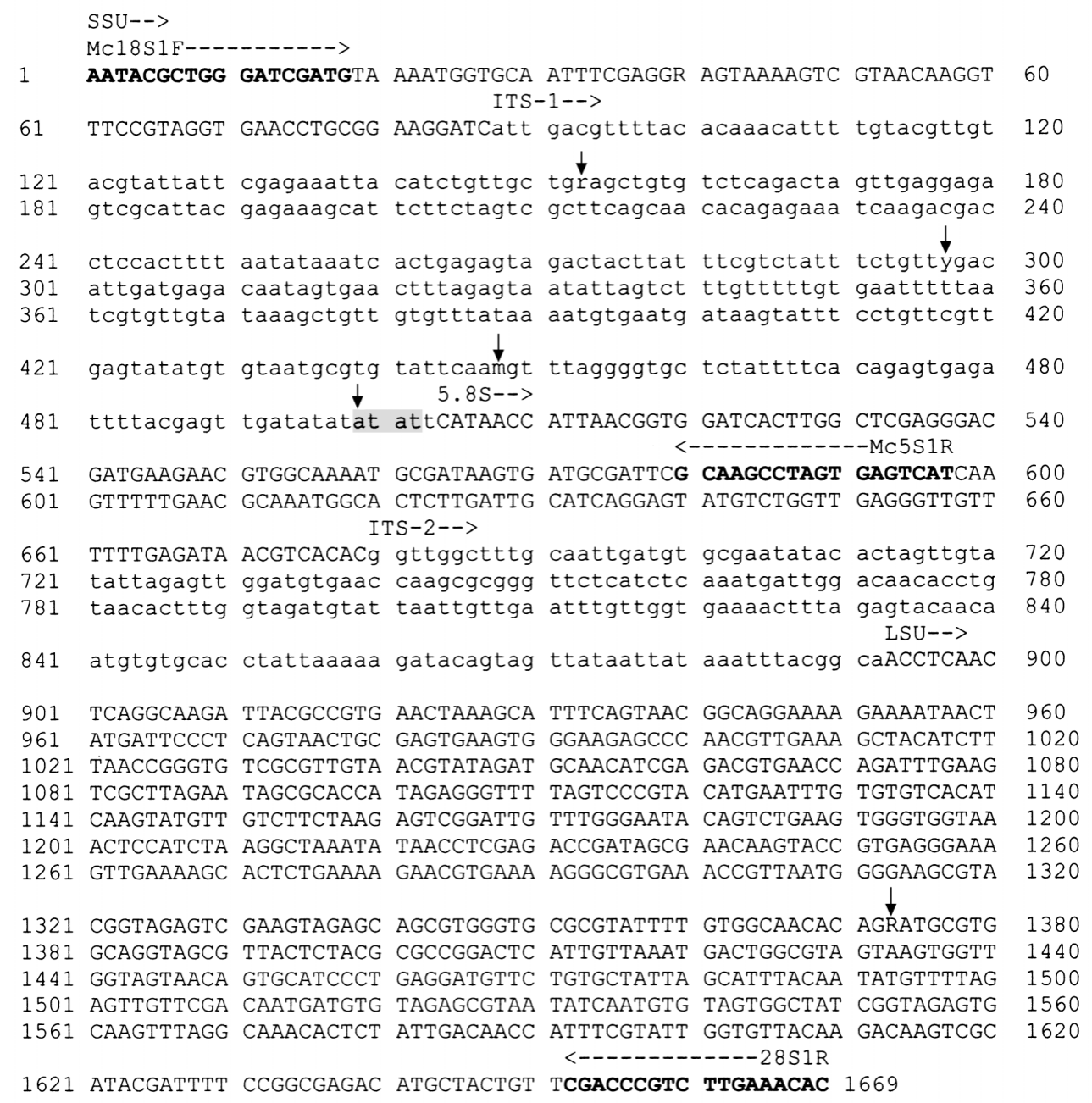

Fig. 2. Myxobolus cerebralis small subunit (SSU), internal transcribed spacer (ITS) regions (lower case letters), and large subunit (LSU) ribosomal DNA sequence. Primer sites are shown in bold, downward arrows mark regions of variability within the ITS-1, insertion/deletion is shaded

bp long and ITS-2 was 213 bp long. No sequence variability was observed within the ITS-2 or 5.8S, and only a single ambiguous base was found in the LSU. Given that some variation was detected in the ITS-1, we decided to continue using this region for comparisons of geographically distinct representatives of $M$. cerebralis.

Another primer, Mc5S1R (5' ATG ACT CAC TAG GCT TGC), complementary to the 5.8S rDNA of Myxobolus cerebralis was used with Mc18S1F to amplify a $600 \mathrm{bp}$ fragment containing the ITS-1. We used these PCR primers to amplify and sequence the ITS-1 from a pool of actinospores as well as from 5 individual spores. Sequences were similar to those obtained by cloning as described above. The ambiguities were clearly visible on the sequence reads, and the sequences became unreadable at the point of the indel near the end of the ITS-1 in both the pooled actinospore sequence and in the sequence from individual actinospores (GenBank accession number AY479925).
These data suggest that there is some ITS-1 sequence variation within a single actinospore. As an actinospore contains multiple cells, we cannot say whether this observed variation occurs within individual cells or between cells of the actinospore. This within-isolate variation has been observed in other invertebrates such as Echinococcus sp. (Bowles \& McManus 1993).

Using the Mc18S1F/Mc5S1R primers, we amplified and sequenced the ITS-1 from Myxobolus cerebralis representatives from West Virginia, Germany and Russia. These sequences were identical to those obtained from the California $M$. cerebralis, including the same ambiguous bases and 3-prime indel. Although this lack of intraspecific variation within the ITS is not uncommon (Hoste et al. 1993, van Herwereden et al. 2000), it seems unlikely that these sequences would be identical for such geographically distinct representatives had the parasite spread naturally over time. For example, it is most likely that Kudoa thyrsites has dispersed naturally over time, and there is as much as 
$43.5 \%$ sequence difference in the ITS-1 region between different geographic representatives of this cosmopolitan marine myxozoan around the world (Whipps \& Kent 2003).

Our reevaluation of the ITS rDNA of Myxobolus cerebralis provides strong support for the already widely accepted hypothesis that the parasite has spread from a single source in recent times. We also observed identical $M$. cerebralis ITS-1 sequences from Germany and Russia, the area that Hoffman (1970) considered to be the parasite's endemic range. This suggests there had been recent introductions and/or mixing of $M$. cerebralis populations throughout Eurasia because we assume that populations with a long history of reproductive isolation would have very different ITS-1 sequences (as seen for Kudoa thyrsites).

We have determined through reevaluation of the existing ITS sequences on GenBank that nearly all of reported sequence by Andree et al. (1999) is a conserved region near the 3-prime end of the SSU rDNA. Despite this initial misidentification, comparisons of the true ITS-1 sequences we generated provide a similar conclusion, and only minor variations occurred in all of the geographic representatives we examined. These results provide further evidence to support the hypothesis for a recent introduction of Myxobolus cerebralis from Europe to the USA

Acknowledgements. We thank Jerri Bartholomew for helpful comments on this manuscript.

\section{LITERATURE CITED}

Altschul SF, Gish W, Miller W, Myers EW, Lipman DJ (1990) Basic local alignment search tool. J Mol Biol 215:403-410 Andree KB, El-Matbouli M, Hoffman RW, Hedrick RP (1999) Comparison of $18 \mathrm{~S}$ and ITS-1 rDNA sequences of selected geographic isolates of Myxobolus cerebralis. Int J Parasitol 29:771-775

Bartholomew JL, Reno P (2002) The history and dissemination of whirling disease. In: Bartholomew JL, Wilson JC (eds)

Editorial responsibility: Wolfgang Körting,

Hannover, Germany
Whirling disease: reviews and current topics. Am Fish Soc Symp 29. American Fisheries Society, Bethesda, MD, p 3-24

Bowles J, McManus DP (1993) Molecular variation in Echinococcus. Acta Trop 53(3-4):291-305

Gilbert MA, Grannath WO (2003) Whirling disease of salmonid fish: life cycle, biology, and disease. J Parasitol 89:658-667

Hedrick RP, El-Matbouli M, Adkison MA, MacConnell E (1998) Whirling disease: re-emergence among wild trout. Immunol Rev 166:365-376

Hoffman GL (1970) Intercontinental and transcontinental dissemination and transfaunation of fish parasites with emphasis on whirling disease (Myxosoma cerebralis) and its effects on fish. In: Snieszko SF (ed) Symposium on diseases of fisheries and shellfish. Am Fish Soc, Bethesda, Spec Publ No. 5, p 69-81

Hoste H, Gasser RB, Chilton NB, Mallet S, Beveridge I (1993) Lack of intraspecific variation in the second internal transcribed spacer (ITS-2) of Trichostrongylus colubriformis ribosomal DNA. Int J Parasitol 23:1069-1071

Kent ML, Andree KB, Bartholomew JL, El-Matbouli M and 12 others (2001) Recent advances in our understanding of the Myxozoa. J Eukaryot Microbiol 48:395-413

Thompson JD, Gibson TJ, Plewniak F, Jeanmougin F, Higgins DG (1997) The ClustalX windows interface: flexible strategies for multiple sequence alignment aided by quality analysis tools. Nucleic Acids Res 24:4876-4882

van Herwerden L, Gasser RB, Blair D (2000) ITS-1 ribosomal DNA sequence variants are maintained in different species and strains of Echinococcus. Int $\mathrm{J}$ Parasitol 30: 157-169

Whipps CM, Kent ML (2003) Analysis of myxozoan ribosomal DNA sequences supports recent spread of Myxobolus cerebralis from Europe to North America. Am Fish Soc Fish Health Section 2003 Annual Meeting \& 44th Western Fish Disease Workshop, Seattle, July 15-17, 2003. Whirling Disease Foundation, Bozeman, MT

Whipps CM, Adlard RD, Bryant MS, Lester RDG, Findlay V, Kent ML (2003) First report of three Kudoa species from Eastern Australia: Kudoa thyrsites from Mahi mahi (Coryphaena hippurus), Kudoa amamiensis and Kudoa minithyrsites n. sp. from Sweeper (Pempheris ypsilychnus). J Eukaryot Microbiol 50:215-219

Whipps CM, Grossel G, Adlard RD, Yokoyama H, Bryant MS, Munday BL, Kent ML (2004) Phylogeny of the Multivalvulidae (Myxozoa: Myxosporea) based upon comparative rDNA sequence analysis. J Parasitol 90:618-622

Wolf K (1986) Salmonid whirling disease: status in the United States, 1985. J Wildl Dis 22:295-299

Submitted: December 17, 2003; Accepted: April 15, 2004 Proofs received from author(s): June 30, 2004 